\title{
Los derechos humanos como límites al poder público y privado: otra vía de fundamentación
}

Carlos R. Asúnsolo-Morales*

Máster en Estudios Avanzados de Derechos Humanos, Universidad Carlos III de Madrid. Investigador, Centro de Estudios sobre la Enseñanza y el Aprendizaje del Derecho, Monterrey, México.

Correo electrónico: carlosam@ceead.org.mx

Recibido: 8 de junio del 2015 Aprobado: 30 de julio del 2015

Cómo citar este artículo: Carlos R. Asúnsolo-Morales. Los derechos humanos como límites al poder público y privado: otra vía de fundamentación. DIxI 22. Diciembre 2015. Pág. 95. doi: http://dx.doi. org/10.16925/di.v17i22.1244

\section{Resumen}

Punto de vista: la participación de empresas multinacionales en violaciones a los derechos humanos se ha considerado, históricamente, un problema de ética empresarial y no un problema de Derecho. Propósito: el principal objetivo del presente artículo es identificar algunas de las dificultades que una concepción tradicional de los derechos humanos, como algo que concierne únicamente a los poderes públicos, enfrenta en el proceso de globalización hegemónica. Descripción: a través de un análisis histórico-sociológico del concepto de derechos humanos, en un primer apartado, se intentará poner en evidencia su configuración histórica como límites al poder público, excluyendo a los poderes privados de dicha concepción. En un segundo apartado, a la luz del proceso de globalización económica, se pretende contrastar la concepción tradicional de los derechos humanos con la nueva dinámica global, haciendo énfasis en las fisuras que dicha concepción presenta. Conclusiones: se abordan algunas claves sobre las cuales se debe profundizar para ampliar la visión de los derechos humanos, incluyendo a los poderes privados y las empresas multinacionales.

Palabras clave: derechos humanos, empresas multinacionales, globalización, límites, poder. 


\title{
Human Rights as Limits of Public and Private Power: Another Type of Foundation
}

\begin{abstract}
Point of view: Participation by multinational companies in human rights violations has historically been considered a problem of business ethics rather than a problem of law. Purpose: The main objective of this article is to identify some of the difficulties that a traditional human rights conception, as something that only concerns governments, faces in the process of hegemonic globalization. Description: Using a historic-sociological analysis of the concept of human rights, the first part aims to show its historical configuration as limits upon governmental power, excluding private powers from that conception. In a second part, in light of the economic globalization process, it aims to contrast the traditional human rights conception with the new global dynamic, placing emphasis on the fissures that such a conception involves. Conclusions: Certain key aspects are addressed as the basis for broadening the vision of human rights, including private powers and multinational companies.
\end{abstract}

Keywords: human rights, multinational companies, globalization, limits, power.

\section{Os direitos humanos como limites ao poder público e privado: outra forma de fundamentação}

\section{Resumo}

Ponto de vista: a participação de empresas multinacionais em violações aos direitos humanos foi considerada, historicamente, um problema de ética empresarial e não um problema de Direito. Propósito: o principal objetivo do presente artigo é identificar algumas das dificuldades que uma concepção tradicional dos direitos humanos, como algo que concerne unicamente aos poderes públicos, enfrenta no processo de globalização hegemônica. Descrição: por meio de uma análise histórico-sociológica do conceito de direitos humanos, numa primeira seção, será destacada sua configuração histórica como limites ao poder público excluindo os poderes privados dessa concepção. Numa segunda seção, à luz do processo de globalização econômica, pretende-se contrastar a concepção tradicional dos direitos humanos com a nova dinâmica global enfatizando as fissuras que essa concepção apresenta. Conclusões: abordam-se alguns aspectos-chave sobre os quais se deve aprofundar para ampliar a visão dos direitos humanos e que incluam os poderes privados e as empresas multinacionais.

Palavras-chave: direitos humanos, empresas multinacionais, globalização, limites, poder. 


\section{INTRODUCCIÓN: UN MUNDO DESIGUAL}

Intentar describir el mundo contemporáneo es una tarea compleja. Sobre todo, porque no es posible encontrar justificaciones aceptables a la realidad. De acuerdo con datos de oxfAM Intermón, para el 2016, el $1 \%$ más rico de la población mundial tendrá más que el resto. Además, las 80 personas más ricas del mundo poseen tanta riqueza como los 3500 millones de personas más pobres ${ }^{1} \mathrm{y}$, según datos del Banco Mundial, un quinto de la población mundial vive con menos de un dólar al día. La situación de desigualdad extrema se ve confirmada por el Foro Económico Mundial que señala el aumento de la desigualdad en ingresos como la segunda mayor amenaza para la humanidad. ${ }^{2}$

El aumento en las condiciones de desigualdad contrasta con el hecho de que hoy existen más empresas que en ninguna otra época. Además, las 500 multinacionales más grandes del mundo concentran el 25\% de la producción mundial y casi la mitad del comercio a escala globall, ${ }^{3}$ y algunas llegan a poseer un Producto Interno Bruto superior al de países enteros. La concentración de riqueza en unos pocos centros de decisión es cada vez mayor. Vivimos en un mundo desigual, donde conviven la abundancia y la miseria. ${ }^{4}$

La gran desigualdad económica y la excesiva concentración de riqueza en pocas manos, además de ser moralmente cuestionables, repercuten negativamente en las instituciones del Estado. Dichas condiciones agudizan los problemas sociales y agravan otro tipo de desigualdades que se manifiestan en la precaria protección de los derechos humanos y generan un desgaste en los sistemas de legitimación del Estado.

No se pretende insinuar que las empresas sean las principales responsables de la situación de desigualdad existente, pero sí remarcar la importancia que tiene analizar la figura de las multinacionales y la relación que sus actividades tienen con el disfrute

1. Véase OXFAM. Riqueza, TENERLO TODO Y QUERER MÁs. (Enero de 2015).

2. Véase World Economic Forum. The outlook on the global AGENDA. World Economic Forum. (2013).

3. Juan Hernández Zubizarreta. LAS EMPRESAS TRANSNACIONALES FRENTE A LOS DERECHOS HUMANOS: HISTORIA DE UNA ASIMETRÍA NORMATIVA: DE LA RESPONSABILIDAD SOCIAL CORPORATIVA A LAS REDES CONTRAHEgEMÓNICAS TRANSNACIONALES. Hegoa. (2009). Pág. 113.

4. Véase Silvina Ribotta. El malestar del mundo actual. Revista Universitas de Filosofía, Derecho y Política 8. (Julio de 2008). Pág. 55 de los derechos humanos como una exigencia imperante, tanto en el mundo académico como en el práctico.

Hoy en día las empresas multinacionales han adquirido una gran relevancia a nivel mundial y cuentan con una gran influencia económica, política, social y jurídica. Ante ello existen serias dificultades en la regulación jurídica de sus actividades a nivel internacional y al imponerles obligaciones en materia de derechos humanos.

Una de las razones por las cuales existen dificultades para regular a las empresas en dicho ámbito, es que su participación en situaciones que vulneran los derechos humanos se ha considerado, primordialmente, un problema de ética empresarial, disciplina desde la que se trabaja el tema hace 40 años y que "nace por imperativo de una realidad social que necesitaba respuestas multidisciplinares". ${ }^{5}$ Sin embargo, reducir y abordar el tema solamente desde ese enfoque hoy en día resulta insuficiente.

Partiendo de la premisa según la cual no sólo el poder político tiene la capacidad para limitar el ejercicio de los derechos humanos, ni es el único responsable en su garantía, en el presente artículo analizaremos la relación entre las empresas y los derechos humanos desde una concepción propia de los derechos, y no sólo desde la ética empresarial como históricamente se ha hecho.

Para ello, es necesario hacer un análisis histórico-sociológico de los orígenes del concepto de derechos humanos como límites al poder, así como de la evolución que a lo largo del tiempo han tenido como algo que concierne principalmente a los poderes públicos. Es decir, analizar el concepto de derechos humanos como una idea propia de la modernidad que, de acuerdo con las circunstancias específicas, justifica su función reivindicadora frente al poder público y se fundamenta en las teorías contractualistas del siglo XVIII.

El objetivo primario del artículo es identificar algunas de las dificultades que implica la concepción tradicional de los derechos humanos - como algo que concierne primordialmente a los poderes públicos- frente a la época de globalización que hoy se afronta.

Conscientes de las limitaciones del presente trabajo, se intenta poner en evidencia cómo la cuestión de empresas y derechos humanos no es simplemente

5. Véase Adela Cortina. La dimensión pública de las éticas aplicadas. Revista Iberoamericana de Educación 9. 2000. Pág. 46. 
un problema de ética empresarial, sino un problema de derechos que demanda una especial atención y representa un enorme desafío.

Como punto de partida, es necesario asumir una concepción de los derechos humanos que aporte sentido y coherencia al resto de argumentos que se irán desarrollando: los derechos humanos como límites al poder y como obligaciones de interferencia. Es decir, como libertad negativa y libertad positiva en la conceptualización elaborada por I. Berlin. ${ }^{6}$

La posición presentada en este artículo se justifica en que los derechos humanos, como obligaciones de interferencia y no sólo de abstención, son los instrumentos idóneos para la construcción de sociedades con un mayor grado de libertad, igualdad y justicia, a través de la implementación de mecanismos que protejan la dignidad inherente a todas las personas.

\section{LOS DERECHOS HUMANOS COMO} LÍMITES AL PODER

La responsabilidad de proteger los derechos humanos, así como de generar las condiciones necesarias para su ejercicio recae, indiscutiblemente, en los poderes públicos. La explicación se encuentra bajo una concepción histórica del concepto en la que dicho poder era la principal amenaza para los ciudadanos. En este orden de ideas, los derechos humanos, desde un punto de vista histórico, surgen como consecuencia de las exigencias sociales de limitar el poder (llámese monarquía o Estado absoluto). ${ }^{7}$

Como es bien conocido, la idea de Estado en sentido moderno se forma en el período comprendido entre los siglos Xııı y xviII. Fue en la transición entre la época feudal y la modernidad cuando el pensamiento ilustrado se encargó de elaborar un relato acerca de la naturaleza del poder político que se basara no en la fe, sino en la razón. Dicho relato continúa vigente hoy en día y ha servido como instrumento legitimador de los sistemas políticos que hoy prevalecen. ${ }^{8}$

La elaboración del relato político fue gradual, con avances, retrocesos y aportaciones valiosas que se

6. Véase Isaiah Berlin. Cuatro ensayos sobre la libertad Alianza Editorial. (1988).

7. Véase Rafael Asís Roig. LAS PARAdoJAS DE LOS DERECHOS FUNDamentales como límites al poder. Dykinson. (2000). Pág. 17. 8. Véase Juan Ramón Capella. Fruta PROHibida: UNA APROXIMACIÓN HISTÓRICO-TEORÉTICA AL ESTUDIO DEL DERECHO Y DEL Estado. Trotta. (1997). Págs. 106-109. fueron puliendo poco a poco. Desde Thomas Hobbes - quien a mediados del siglo XVII pone las bases con su obra Leviatan (aunque no fue el primero) -, hasta Immanuel Kant, con su obra Crítica de la razón pura de finales del siglo XviII, con quien se pudiera decir que se completa dicho relato. Existe un amplio consenso en situar el origen del Estado moderno en la filosofía política de I. Kant. ${ }^{9}$

No se pretende hacer un análisis del tránsito a la modernidad y del largo proceso de evolución de los derechos, tema sobre el cual existen numerosos trabajos. Al abordar el tema, la intención es remarcar factores como la aparición del sistema económico capitalista, el ascenso de la clase burguesa, la aparición del Estado y el nuevo Derecho producido por el poder político. Es sobre estos elementos que se va construyendo la idea de los derechos humanos como límites al poder. ${ }^{10}$

En concreto, fue con la aparición del Estado absoluto que se originó la fórmula de los derechos fundamentales como límites al poder. Un Estado absoluto, que no reconocía poder superior y que monopolizó el uso de la fuerza, generaría un desacuerdo entre la burguesía y la monarquía acerca de las condiciones en que se ejercía y se justificaba dicho poder. Este disenso marcaría la entrada de las luchas revolucionarias en Francia y la lucha de independencia en los Estados Unidos de América.

Tanto en la declaración francesa como en los textos de las colonias americanas, los derechos del hombre se formulan, ante todo y en primer lugar, como límites y obligaciones del poder público. ${ }^{11} \mathrm{La}$ configuración de los derechos fundamentales como límites al poder o como verdaderas obligaciones del Estado, y su consiguiente inclusión en normas jurídicas, no es una condición natural de las libertades, sino una condición histórica que atiende a una confluencia de circunstancias de índole económica, política y social.

Se debe tener en cuenta que las luchas revolucionarias, tanto en Francia como en Estados Unidos,

9. Véase Antonio Enrique Pérez Luño. Kant y los Derechos Humanos. Primera parte: El papel de Kant en la formación histórica de los derechos humanos. Dirs. Gregorio Peces-Barba Martínez, Eusebio Fernández García y Rafael Asís Roig. Historia de los Derechos Fundamentales. Tomo iI: Siglo XViII. Volumen iI: LA filosofía de los Derechos Humanos. Dykinson. (2001). Págs. 450 y 452. 10. Véase Gregorio Peces-Barba. Curso de derechos fundamentales. Teoría general. Colaboración de Rafael Asís Roig, Carlos Fernández Liesa y Ángel Llamas Cascón. Universidad Carlos III de Madrid. Boletín Oficial del Estado. (1999).

11. Véase Luis Prieto Sanchís. Estudios SOBRE DEREChos FUNDAMENTALES. Editorial Debate. (1990) 
no buscaban la alternancia de los grupos que ocupaban el poder, sino la suplantación completa en la forma como dicho poder se constituía. Es decir, la ciudadanía desconocía la legitimidad del poder político y del Estado, y los reclamaba para sí misma. Dicho reclamo se basaba en las teorías contractualistas que remarcaban el binomio Estado-sociedad civil, las cuales, básicamente, describen la vida en sociedad como el producto de un contrato en el que los individuos se organizan por medio de autoridades públicas. Ello tuvo como consecuencia la interiorización de las normas del Derecho natural al Derecho positivo, su plasmación en un orden jurídico superior y la creación de mecanismos que vigilaran su cumplimiento. ${ }^{12}$

De esta forma, las autoridades públicas no podrían actuar en contra de los derechos naturales de los ciudadanos, y en caso de hacerlo, estarían violando el "contrato social", ${ }_{13}^{3}$ construcción teórica de Jean Jacques Rousseau, o el "contrato originario" en la terminología de I. Kant, de manera que los ciudadanos no tendrían la obligación de obedecer ya que dichas normas carecerían de legitimidad.

Bajo dicha construcción se descarta, dadas las circunstancias específicas en las que el poder político era la principal amenaza, el hecho de que entre individuos también existan jerarquías de poder y que, incluso, ciertos agentes privados pudieran sobrepasar los poderes públicos. En este sentido, en la división entre sociedad civil y Estado, se le atribuye a este último la responsabilidad exclusiva de garantizar los derechos humanos. La importancia que dicha distinción tiene, en relación con los objetivos planteados en el presente trabajo, es la obligación de no interferencia del Estado en las relaciones entre particulares, ya que de hacerlo implica el riesgo de afectar los derechos naturales de las personas. Se trata de un Estado mínimo que únicamente se encargue de garantizar el respeto de las normas, pero sin intervenir en los ámbitos privados.

Lo que aquí interesa remarcar es que los avances en la evolución de los derechos humanos se derivaron de una concepción que en determinado momento se volvió insuficiente para satisfacer las exigencias sociales. ${ }^{14}$ Dicho así, los derechos humanos se han

12. Véase Francisco Javier Ansuategui Roig. Derechos fundamentales y tradiciones constitucionales comunes en la aplicación del Derecho Europeo. Papeles el Tiempo de los Derechos 3. 2013. Pág. 1.

13. Véase Jean Jacques Rousseau. Contrato Social. Colección Austral. (2001).

14. Véase Ignacio Aymerich Ojea. Orígenes ideológicos de la distribución de responsabilidades públicas y privadas en la garantía de los derechos humanos. Eds. Francisco Javier Zamora, Jesús García construido, principalmente, como respuestas a las amenazas de la libertad y el patrimonio de los individuos. Estas exigencias se articulan a través de la limitación del poder y de su intervención protectora, es decir, abstenerse de vulnerar e intervenir a fin de proteger.

Si bien los poderes públicos cuentan con una responsabilidad directa en relación con la protección de los derechos humanos, los poderes privados también pueden, y deben, contribuir a aumentar otro tipo de posibilidades que repercutan en su ejercicio. Derechos tales como la libertad de expresión, el derecho a la alimentación, el derecho a la salud o a un medio ambiente sano, entre otros, se encuentran estrechamente relacionados con actividades comerciales de las empresas.

No se busca situar a las empresas en el mismo grado de responsabilidad que los poderes públicos en lo que respecta a la garantía efectiva de los derechos humanos; es decir, no es que una empresa deba garantizar el derecho a la libertad de expresión a través del establecimiento de mecanismos jurídicos a fin de proteger, sancionar y remediar. Sin embargo, sí es importante remarcar que encuadrar la responsabilidad de garantizar la protección y el ejercicio efectivo de los derechos humanos solamente a los poderes públicos resulta insuficiente.

La responsabilidad de garantizar efectivamente los derechos no recae sólo en los Estados y, por tanto, los intereses de las empresas deben ajustarse a esta exigencia, al menos, en lo que se refiere al impacto que sus actividades tienen en el ejercicio de los derechos humanos. Esto guarda una estrecha relación con los distintos modelos políticos e ideológicos, como el liberal o el socialdemócrata.

En términos generales, por un lado se encuentra la corriente del pensamiento liberal, la cual concibe los derechos fundamentales como límites y prohibiciones negativas oponibles únicamente al poder político, y que han servido como base en la construcción del modelo del Estado de Derecho como "Estado mínimo", dedicado solamente a garantizar las libertades de los individuos a través de la no interferencia en el ámbito privado de los ciudadanos. Y, por otro, el modelo del Estado Social de Derecho, formulado en las constituciones de la segunda mitad del siglo $\mathrm{xx}$, el cual previene un sistema de derechos

Cívico y Lorena Sales. LA RESPONSABILIDAD DE LAS MULTINACIONALES POR VIOLACIONES DE LOS DERECHOS HUMANOS. Cuadernos de la Cátedra Democracia y Derechos Humanos. (2013). 
sociales y deberes de interferencia. Conocido como "Estado máximo", su fin es establecer las condiciones necesarias que garanticen el ejercicio de los derechos y satisfacer las necesidades básicas de las personas. ${ }^{15}$

Lo que cabe remarcar es cómo, bien sea en su versión liberal-democrática o en la socialdemocrática, el único poder frente al cual se han justificado las garantías, es decir, los límites y los vínculos para tutelar los derechos fundamentales de sus titulares, es el poder público. En este sentido, "la expresión Estado de Derecho es por lo demás emblemática: sólo el Estado es sujeto frente al cual se justifican reglas, prohibiciones y obligaciones dirigidas a impedir los abusos que dañan los derechos fundamentales". ${ }^{16}$ De acuerdo con esta lógica, son los poderes públicos los que deben someterse al Derecho, y no los poderes privados.

El pensamiento liberal sitúa el derecho de propiedad y la libertad contractual como derechos del mismo nivel que las libertades fundamentales. Dicha concepción "ha triunfado hoy más que nunca". ${ }^{17}$ Es una versión incompleta de los derechos humanos que, si bien incluye los derechos civiles y políticos, prescinde de los económicos, sociales y culturales. Una concepción de este tipo rechaza la existencia de poderes de facto y de jerarquías de fuerza en las relaciones entre privados.

Es importante comprender que detrás de la tradición liberal existe una operación teórica que tiene raíz en sus orígenes, la cual se irradia en toda la cultura jurídica y política: la concepción de que el poder solamente se encuentra en el ámbito público y que sólo corresponde a los Estados y autoridades públicas someterse al Derecho a través de la imposición de límites, normas y controles. De esta forma, las libertades de la sociedad civil y el mercado sólo tendrían que protegerse contra la única amenaza previsible desde esta concepción: los poderes públicos. De acuerdo con Ferraloji, "esta concepción restringida del poder es del todo insostenible". ${ }^{18}$

15. Véase Norberto Bobbio. Liberalismo y democracia. Fondo de Cultura Económica. (1993). Pág. 7.

16. Véase Luigi Ferrajoli. Contra LOS PODERES SALVAJES DEL MERCADO: PARA UN CONSTITUCIONALISMO DE DERECHO PRIVAdo. Disponible en http://biblio.juridicas.unam.mx/libros/1/349/8.pdf. Pág. 100

17. Id. Pág. 101.

18. Id.

\section{GLOBALIZACIÓN: UN NUEVO} PANORAMA

El análisis de los derechos humanos no está completo si no se hace a la luz de la realidad y de las dificultades que existen para implementar dichas pretensiones morales. ${ }^{19}$ Esta realidad, en términos generales, es el fenómeno de globalización en sus distintas vertientes y la influencia que dicho proceso tiene en los derechos humanos.

Hablar de la relación de los derechos humanos y las empresas lleva, forzosamente, a hablar de la globalización que se vive en el siglo xxI, ya que es bajo este nuevo contexto de espacio y tiempo en el que tienen lugar las interacciones entre los distintos actores en el plano internacional, incluyendo a las multinacionales como agentes centrales del desarrollo económico con una gran influencia política, social y jurídica.

De acuerdo con Wayne Ellwood, la globalización es el concepto del que más se ha hablado y menos se ha comprendido en el nuevo milenio. Es un término novedoso que describe un proceso antiguo. El proceso se puede rastrear al inicio de la época colonial europea y tiene como finalidad integrar la economía mundial. ${ }^{20}$

En este sentido, el término globalización se ha convertido en un concepto que se escucha prácticamente en todos lados. Es utilizado en diversos contextos y ámbitos, bajo un sinfín de concepciones y aproximaciones distintas, desde diversos enfoques, a veces cargado de cierta emotividad ideológica $y$, otras tantas, para enraizar el discurso en la comentocracia común, pero difícilmente se puede encontrar un significado único $y$, mucho menos, uno fácil de aclarar. Por eso siempre que se habla de globalización, es necesario hacerlo en función del tipo de proceso al que se hace referencia. Es decir, globalización, sí; pero ¿de qué?

Hablar de globalización es hablar de un conjunto de relaciones sociales que se encuentran en constante cambio y, por tanto, necesariamente entran en conflicto. Tampoco corresponde a las pretensiones de este trabajo dar un concepto definitivo, ni mucho menos cerrado de la globalización. En todo caso, debe ser entendida como una serie de procesos en construcción, dinámicos y en marcha, de los cuales sólo es posible ofrecer determinadas características que forman parte

19. Véase Gregorio Peces-Barba, supra, nota 10. Pág. 108.

20. Véase Wayne Ellwood. Globalización. Intermon Oxfam. (2005). Pág. 17. 
de estos. Cualquier concepto exhaustivo deberá ser siempre procedimental y no sustantivo.

Dicho así, simplemente, el concepto de globalización termina por ser un término que intenta explicar la actualidad de los ámbitos económico, político, jurídico y social, y las relaciones e intercambios que se llevan a cabo entre ellos. Basta con hacer un breve repaso de algunos de los estudios sobre el fenómeno de la globalización ${ }^{21}$ para darse cuenta de que es un proceso polifacético, con dimensiones económicas, sociales, políticas, culturales, religiosas y jurídicas que se combinan entre sí de formas extremadamente complejas. De Sousa Santos señala que dichas interacciones han tomado tales proporciones que se considera que se ha inaugurado un nuevo periodo de desarrollo social. ${ }^{22}$

Ante la divergencia de las características que componen el fenómeno de la globalización, resulta sumamente complejo definirlo, incluso de forma abstracta. Es común asimilar el término al nuevo ámbito económico mundial, a partir del cual se ha globalizado la producción de bienes, servicios y mercados financieros. Sin embargo, una concepción enfocada solamente en el ámbito económico resultaría incompleta a fin de abordar el estudio de las empresas y los derechos humanos: "El problema es que actualmente confundimos la globalización económica como la única globalización existente y, lo que resulta mucho más preocupante, la única globalización realmente posible". ${ }^{23}$

La globalización también debe ser abordada desde perspectivas tales como la social, la política y la jurídica. Dichos ámbitos no deben ser entendidos y mucho menos explicados aislados uno del otro, sino que se ha de tener una concepción reticular del proceso de globalización en la que los diversos campos son interdependientes el uno del otro, ya que las acciones que se dan en determinado ámbito tienen consecuencias - muchas veces inmediatas - en los otros. El estudio de la globalización demanda una confluencia interdisciplinar. ${ }^{24}$

21. Véase David Held y Anthony McGrew. Globalización/ ANTIGLOBALIZACIÓN: SOBRE LA RECONSTRUCCIÓN DEL ORDEN MUNDIAL. Paidós. (2003)

22. Véase Boaventura de Sousa Santos. Sociología Jurídica CRÍtica: PARA Un NUEVo SENTIDo COMÚN DEL DERECHO. Editorial Trotta. (2008). Pág. 302.

23. Véase Felipe Gómez Isa. Derechos humanos y globalización. Congreso El desafío del desarRollo de los DERECHOS HUMAnos. Propuestas locales para otra globalización. Hegoa. (2007). Pág. 2.

24. Véase María José Fariñas Dulce. Globalización, ciudadanía y derechos humanos. CUADERnos "BARTOlOMÉ DE LAS CASAs" DEI
De Sousa Santos define la globalización como el "proceso a través del cual una determinada condición o entidad local amplía su ámbito a todo el globo y, al hacerlo, adquiere la capacidad de designar como locales las condiciones o entidades rivales" ${ }^{25}$ Es decir, las circunstancias globales no son dadas por una casualidad y pocas veces existe un consenso acerca de lo que debe o no ser global. "No existe una globalización genuina", sino que existe una "globalización exitosa de un localismo dado" ${ }^{26}$ Como consecuencia, toda circunstancia global tiene un origen determinado, una fuente específica de arraigo cultural.

En esta definición y, en general, en cualquier definición aceptable del fenómeno de la globalización también entra en juego, debido a la intensificación de las relaciones y a la aceleración de los acontecimientos en todo el globo, la transformación y comprensión del concepto espacio-tiempo. Este proceso social de espacio-tiempo provoca ciertas asimetrías en los procesos de globalización que aplican a fenómenos distintos, y pueden ser divididos - en la misma sintonía de ideas - en dos dimensiones: por un lado, se encuentran los denominados localismos globalizados, por los que un fenómeno local determinado es transnacionalizado con éxito (las empresas multinacionales son un ejemplo paradigmático en este sentido, el idioma inglés convertido en lengua vehicular o los fenómenos culturales como la música popular norteamericana); y, por otro lado, se encuentran los globalismos localizados, que se refieren al impacto específico de las prácticas y los imperativos globales en las condiciones locales, las cuales tienden a desestructurarse y a adecuarse a los fines de dichos imperativos globales (el ejemplo más claro son las reformas del libre comercio, la deforestación y el deterioro masivo de los recursos naturales para el pago de la deuda externa). ${ }^{27}$

En este sentido, los países centrales se especializan en localismos globalizados tales como el consumo masivo, los restaurantes de comida rápida, marcas de ropa y otros rasgos propios de la cultura occidental. Mientras que a los países periféricos les son impuestos los globalismos localizados, tales como la desregulación de sus mercados, las formas de producción fordistas y posfordistas, o la explotación de recursos naturales a través de la inversión extranjera directa. Estos procesos son impuestos a través de prácticas

Instituto de Derechos Humanos "Bartolomé de las Casas". Dykinson. (2000). Pág. 2.

25. Véase Boaventura de Sousa Santos, supra, nota 22. Pág. 310.

26. Id.

27. Id. 
adaptativas, como lo son las reformas estructurales, y son transmitidos mediante audiencias adaptativas a través del ejercicio político local que actúa en favor de los intereses de los "localismos globalizados triunfantes". ${ }^{28}$

Es posible identificar elementos que se han convertido en globales y que confeccionan el plano mundial: la democracia formal basada en el Estado de Derecho como Estado mínimo, la cual somete el sistema político al económico; la consolidación global de la economía capitalista como una nueva fase de desarrollo histórico en el sistema mundial; la concentración de poder y capital en manos de las empresas como agentes estratégicos del sistema económico; la consecuente flexibilización y desregulación jurídica que se refleja en la nueva división internacional del trabajo; la consolidación de los derechos humanos de carácter individual desde una concepción liberal que no representa ningún límite en contra de la libertad de mercado; el sistema global de comunicaciones como consecuencia de la revolución tecnológica; y una determinada forma de entender la cultura occidental, un monoculturalismo de la sociedad. ${ }^{29}$

Esto no implica que no exista un contrapeso o una resistencia a la imposición de los localismos globalizados o globalismos localizados. Estos contrapesos, definidos como el "cosmopolitismo subalterno", ${ }^{30}$ es posible identificarlos en la organización transnacional en la defensa de los intereses de los Estados-nación subordinados, clases y grupos sociales desprotegidos, a través de los movimientos de la sociedad civil que tienen como objetivo "contrarrestar los efectos dañinos de las formas hegemónicas de globalización". ${ }^{31}$ Movimientos como las organizaciones laborales mundiales, redes internacionales de servicios jurídicos alternativos, el 15-M, Occupy Wall Street y organizaciones de la sociedad civil en defensa de los derechos humanos, entre otros.

En relación con los derechos humanos, en el nuevo contexto espacio-temporal de la globalización han ido surgiendo, a la par de la lucha por el respeto de los derechos económicos, sociales y culturales, nuevas reivindicaciones de derechos primordialmente colectivos, tales como los de carácter étnico, los de grupos socialmente diferenciados o la protección al medio ambiente, entre otros. Derechos que son excluidos por la globalización económica imperante.

\footnotetext{
28. Id.

29. Véase María José Fariñas Dulce, supra, nota 24. Págs. 11-17.

30. Véase Boaventura de Sousa Santos, supra, nota 22.

31. Id.
}

Por último, de acuerdo con la clasificación que se ha venido exponiendo, se encuentran los movimientos en contra de sucesos que amenazan la propia supervivencia de la raza humana. Son considerados movimientos de globalización genuina y se les conoce con el nombre de "patrimonio común de la humanidad" o "herencia común de la humanidad". ${ }^{32}$ Movimientos como la defensa de la Amazonía, en contra del deterioro de la capa de ozono y de la proliferación de armas de destrucción masiva, entre otros.

En este sentido, la globalización no debe ser equiparada con la homogeneización, uniformación o unificación, sino todo lo contrario, lejos de ser un proceso lineal o sencillo, es altamente contradictorio. El proceso de globalización es por tanto selectivo y dispar, cargado de tensiones y contradicciones, y conserva la jerarquía del sistema mundial. Es decir, el proceso es dirigido por aquellos países que ostentan una mayor influencia y poderío económico en el plano internacional.

\section{A. Empresas multinacionales y derechos humanos en el contexto de la globalización: claves sobre la cuestión}

La intensificación de las relaciones en el contexto de la globalización agudiza los impactos que la actividad de las empresas multinacionales genera en las condiciones de vida de las personas. La participación de empresas en abusos de derechos humanos se ha sumado a las exigencias sociales para abordar los efectos negativos que dicho proceso genera. En este contexto, el Derecho se enfrenta al reto de dar una respuesta jurídica a los desafíos que impone la nueva dinámica globalizadora. Es sobre este nuevo ámbito de espacio y tiempo que hemos venido describiendo, en el que los derechos humanos deben ser "reinterpretados y re-ideologizados constantemente". ${ }^{33}$

Estos cambios demandan una especial atención en la instrumentalización, configuración y distribución del poder, así como de los impactos que este tiene, en especial en los derechos humanos.

Con la liberalización del comercio internacional, la imposición de políticas privatizadoras y la desregulación económica, el nuevo contexto económico concede grandes beneficios a la actividad de las empresas multinacionales y les confiere un gran

\footnotetext{
32. Id.

33. Véase María José Fariñas Dulce, supra, nota 24. Pág. 1.
} 
poder económico que las posiciona en un lugar privilegiado en la configuración de políticas económicas a nivel global. Este es el paisaje en el que actúan las empresas: la globalización genera enormes beneficios para el desarrollo de las actividades comerciales, pero no las condiciones necesarias para una redistribución más equitativa de los beneficios. De acuerdo con Ribotta, existe una relación problemática entre la globalización económica y los derechos humanos:

La globalización ha contribuido a acrecentar las tendencias que hacen que el $20 \%$ más rico de la población de los países de mayores ingresos realicen el 86\% del consumo privado, mientras que el $20 \%$ más pobre de la población mundial apenas supere el 1\%”. ${ }^{34}$

La globalización, sin duda, ha traído grandes avances tecnológicos y cuantiosos beneficios económicos para las empresas. El problema se encuentra en que dichos efectos no se han reflejado, de forma general, en las condiciones de vida de los individuos, sino todo lo contrario: la globalización ha provocado efectos negativos que aumentan la brecha de desigualdad entre ricos y pobres, y debilita la protección de los derechos humanos. Dichos efectos subyacen al reclamo social de un proceso globalizador más equitativo e incluyente, es decir, de acuerdo con la terminología utilizada por Joseph E. Stiglitz, una "democratización del proceso". 35

La democratización de la globalización "implica hacer frente a diversos problemas de índole política, como la desigualdad y el déficit democrático de las instituciones económicas", ${ }^{36}$ y esto no puede existir sin un verdadero pluralismo económico, cultural y social, más allá de la mera y formal democracia política. ${ }^{37}$ Una globalización genuina de los derechos humanos exigiría la globalización de todos los derechos humanos, no sólo los civiles y políticos, sino también los de carácter económico, social y cultural.

Las desigualdades que provoca la globalización generan una distinción entre aquellos que forman parte del proceso de la economía globalizada y los que son excluidos. Un proceso globalizador homogéneo, basado en principios exclusivamente de carácter liberal e individual, sobre los cuales se fundamenta su legitimidad, excluye y rechaza cualquier otro tipo

34. Véase Silvina Ribotta, supra, nota 4. Pág. 58

35. Joseph E. Stiglitz. Making Globalization work. W.W. Norton \& Company. (2006). Pág. 269.

36. Id.

37. Véase María José Fariñas Dulce, supra, nota 24. Pág. 24 de derechos humanos, en especial los de carácter social, igualitario y redistributivo, que atenten contra dichos principios. ${ }^{38}$ Una globalización de carácter fundamentalmente económico a la que se le suele denominar "globalización neoliberal". ${ }^{39}$ De seguir por este camino, se corre el riesgo de que el mundo se convierta en un auténtico "Apartheid Global". 40

La disminución de los niveles de protección de los derechos estratifica a los sectores sociales más débiles. Además, se generan nuevas formas, directas o indirectas, de vulnerar los derechos humanos como consecuencia de las enormes desigualdades que genera un sistema económico capitalista sin límites. Este proceso ha tenido como consecuencia el debilitamiento progresivo de la protección de los derechos humanos en muchos países, afectando básicamente a los derechos económicos, sociales y culturales.

Asimismo, la desterritorialización y la descentralización que se dan en el proceso de globalización debilitan a los Estados nacionales en relación con su capacidad de decisión política y económica. Los criterios económicos del libre mercado se sobreponen a los principios políticos y normativos que ahora deben ajustarse a las exigencias de los primeros. Los Estados nacionales enfrentan una fuerte crisis de gobernabilidad, lo cual los imposibilita para ofrecer respuestas satisfactorias a la mayoría de los problemas económicos, sociales y jurídicos, lo que genera un problema de desconfianza en la ciudadanía y, por consiguiente, de legitimidad y déficit democrático. ${ }^{41}$

La reconfiguración de las relaciones en el plano internacional, en el que las empresas multinacionales y las instituciones financieras limitan y condicionan la soberanía estatal, así como los poderes fácticos que a nivel interno coartan el ejercicio de dicha soberanía, "son hechos que le han arrebatado al Estado muchos metros en tanto que instancia monopolizadora del poder". 42

En este sentido, la globalización debe implicar "la posibilidad de conciliar los cambios tecnológicos y los acontecimientos económicos con un respeto

\footnotetext{
38. Id.

39. Véase Felipe Gómez Isa, supra, nota 23. Pág. 3.

40. Véase José Manuel Pureza. El PATRIMONIO COMÚN DE LA HUMANIDAD: ¿HACIA UN DERECHO INTERNACIONAL DE LA SOLIDARIDAD? Editorial Trotta. (2002) Pág. 61.

41. Véase María José Fariñas Dulce, supra, nota 24. Pág. 26.

42. Véase Luis M. Alix Lloredo. La filosofía del derecho en tiempo de crisis: en torno al estatus epistemológico de la filosofía jurídica. Revista Telemática del Filosofía del Derecho 16. 2013. Págs. 109-133.
} 
universal de los derechos humanos". ${ }^{43}$ La expansión económica no sólo debe ser congruente con la expansión de los derechos humanos, sino una condición necesaria. El discurso económico no puede ir separado de los conceptos de respeto, protección y promoción de los derechos humanos, ${ }^{44}$ "debe formar parte del argumentativo económico y empresarial", ${ }^{45}$ y ocupar un lugar preponderante en el análisis y la evaluación de la actividad empresarial en particular y de la económica en general. ${ }^{46}$ El crecimiento económico se legitima cuando contribuye al desarrollo de los derechos humanos.

La actividad empresarial, tal como se viene desarrollando en los últimos treinta años, no puede, ni debe, permanecer alejada del desarrollo de los derechos humanos. J. Ansuategui señala que pareciera ser que "las consecuencias de la globalización van en sentido contrario a las exigencias de la universalidad de los derechos: hay incompatibilidad entre la lógica del mercado que está detrás de la globalización y la lógica de los derechos". ${ }^{47}$ Se ha venido dando una mercantilización de los derechos sociales, cuya satisfacción se encuentra sujeta a las leyes del mercado, lo que disminuye su capacidad emancipadora. Una auténtica "privatización de los derechos humanos". ${ }^{8}$

Existe una marcada diferenciación entre cada uno de estos discursos. Por un lado, en el mundo del mercado y de la empresa, las relaciones se rigen a través de los contratos, las transacciones financieras, la ley de oferta y demanda, de beneficio y utilidad económica; mientras que, por otro lado, el discurso de los derechos maneja una semántica distinta e incluso contradictoria, se alejan del ámbito de negociación y se conciben como auténticos triunfos de las mayorías. ${ }^{49}$

Las condiciones de desigualdad, no sólo económica sino también social y cultural, que genera una globalización sin restricciones y límites, ponen en cuestionamiento la validez de los derechos humanos como un estándar común para todas las personas y

43. Véase Matthew J. Gibney. LA GLOBALIZACIÓN DE LOS DERECHOS humanos. Crítica. (2003). Pág. 13.

44. Véase Olga Martín Ortega. LAS empresas MUltinacionales y DERECHOS HUMANOS EN DERECHO INTERNACIONAL. BOSch Internacional. (2008). Pág. 25.

45. Véase Francisco Javier Ansuategui Roig. Derechos humanos y empresa en el contexto de la internacionalización. REVISTA DE Políticas Públicas 1. 2013. Págs. 7-10.

46. Id.

47. Id.

48. Véase Felipe Gómez Isa, supra, nota 23. Pág. 4.

49. Véase Francisco Javier Ansuategui Roig, supra, nota 45. Pág. 10 plantea nuevos retos en la manera en que se formulan, articulan y promueven.

\section{CONCLUSIONES: OTRA VÍA DE FUNDAMENTACIÓN}

La nueva realidad global ha reconfigurado las relaciones de poder en el plano internacional. En este sentido, la promoción y defensa de los derechos humanos ha dejado de ser una responsabilidad exclusiva de los Estados, y ha pasado a ser una responsabilidad compartida entre todos los actores, tanto públicos como privados.

La cuestión que aquí se plantea, en términos generales, es que ante el poder económico, político, social y jurídico que han adquirido algunos de los agentes privados, garantizar el ejercicio efectivo de los derechos humanos no debe depender solamente de los poderes públicos. Es evidente que la pretensión de los derechos humanos como una realidad social está condicionada por elementos de carácter social, económico o cultural que sobrepasan lo jurídico y que influyen en la realización efectiva de los mismos. ${ }^{50}$

Ello implica que la efectividad de los derechos no depende solamente del poder público, sino que también requiere de la imprescindible cooperación de los poderes privados a fin de que dichas condiciones sean una realidad alcanzable para la mayoría.

Como se ha venido señalando, la responsabilidad en materia de derechos humanos se encuentra definida, principalmente, para los poderes públicos. Esta situación no es obra de la casualidad. La garantía del ejercicio efectivo de los derechos humanos se ha construido desde una concepción vertical de la relación entre Estado y ciudadano, la cual excluye las relaciones verticales que de facto existen entre ciudadanos y poderes privados.

La evolución de los derechos en el ámbito privado se ha basado en la gradual imposición de límites a los poderes públicos con el fin de garantizar su tutela; sin embargo, no existe todavía una teoría de los derechos humanos pensada para limitar a los poderes privados. ${ }^{51}$ No al menos una que sea comparable a la elaborada para los poderes públicos.

Para ello sería necesario, en un primer plano, reconocer la existencia de relaciones verticales

50. Véase Gregorio Peces-Barba, supra, nota 10.

51. Véase Luigi Ferrajoli, supra, nota 16. Pág. 105 
de poder en el ámbito privado y no sólo en la relación Estado-ciudadano, ya que la carencia de normas jurídicas que sometan a dichos poderes da lugar a formas de opresión propias de un mercado sin restricciones en el que el más fuerte, en este caso los poderes económicos, someten a los más débiles, los ciudadanos. Opresiones del tipo económico que generan desigualdades. ${ }^{52}$

Aligual que los poderes públicos, que ante la falta de limitaciones tienden a cometer actos arbitrarios y abusivos, los poderes privados no son la excepción. L. Ferrajoli hace valer la tesis de Montesquieu en el Espíritu de las leyes al señalar que ante la falta de límites legales, el poder tiende a acumularse en formas absolutas, ${ }^{53}$ "a diferencia de los poderes regulados, los poderes no regulados son tendencialmente absolutos" ${ }^{54}$ Hoy en día no resulta complicado contrastar esta tesis en el ámbito privado si se tiene en cuenta la concentración de capital y el poder económico que ostentan las grandes multinacionales, situación que agudiza las desigualdades existentes y limita las posibilidades de elección de los ciudadanos. El absolutismo encuentra lugar en los espacios de poder no regulados.

No se pretende insinuar que dichos poderes tengan que ser suprimidos ya que también desempeñan una importante función social, sino solamente plantear la posibilidad de encauzarlos dentro de ciertos límites, y que debería ser el Derecho el instrumento encargado para hacerlo. Si se considera cómo se vive en una época en la que el poder económico se concentra en pocos centros privados y no tanto en las instituciones públicas, se deben imponer límites a dichos poderes, y la vía no puede ser otra que la de los derechos humanos, con la capacidad y fuerza coactiva para sancionar a quienes no los respeten, ${ }^{55} \mathrm{y}$ no la de las buenas intenciones o autorregulaciones, como en el caso de las empresas cuando se habla de su responsabilidad de respetar los derechos humanos.

Esta ha sido la premisa sobre la cual las autoridades públicas garantizan la protección de los derechos fundamentales como resultado del mandato constitucional. La sociedad hoy se encuentra atada a una

52. Id. Pág. 107.

53. Charles de Secondat Barón de Montesquieu. Del espíritu DE LAS LEYES. Tecnos. (1985).

54. Véase Luigi Ferrajoli, supra, nota 16. Pág. 105.

55. Véase Francisco Javier Ansuategui Roig. Democracia constitucional, derechos $y$ violencia institucional. PAPELES EL TIEMPo DE LOS Derechos 3. 2009. Pág. 10. concepción tradicional de los derechos humanos que, en términos de protección de los individuos, presenta los derechos como límites a los poderes públicos. Sin embargo, entre particulares, o mejor dicho, en el ámbito privado, existe un vacío que demanda una mayor consideración. ${ }^{56}$

De acuerdo con la visión que sucinta y superficialmente se ha expuesto, lo que se busca señalar es que el Estado y los poderes públicos no deberían ser los únicos responsables en garantizar el ejercicio efectivo de los derechos humanos. Son también las empresas, como agentes centrales de desarrollo con un gran potencial de afectar los derechos humanos, responsables de ajustar sus conductas a los estándares de cumplimiento de los derechos humanos como aspiración legítima de sus actividades, más allá del mínimo legal establecido.

Lo que propone L. Ferrajoli es la expansión del Estado de Derecho, tanto en su versión liberal como en la social, "al mayor número de ámbitos de vida y esferas de poder, en las que también estén tutelados y satisfechos los derechos fundamentales de las personas". ${ }^{57}$ Esta tesis presenta grandes conflictos e interrogantes que lamentablemente no se pueden abordar en este artículo, pues su propósito es sólo remarcar cómo también los poderes privados pueden limitar el ejercicio de la libertad y agudizar las desigualdades entre ciudadanos, y cómo esto demanda especial atención por parte de la filosofía de los derechos fundamentales y del Derecho en general. La forma en la que se podría articular la imposición de dichos límites en el Estado de Derecho debe ser objeto de investigaciones posteriores.

Se ha observado de qué manera por un largo periodo de tiempo se concebían los derechos como algo exclusivo de las relaciones verticales entre el binomio sociedad civil-Estado, entre individuos y poderes públicos, dejando las relaciones entre particulares, es decir, el ámbito privado, excluido de dicha concepción. Hoy la dinámica de la globalización, la posición que ocupan los derechos en las constituciones y el desarrollo del Derecho Internacional de los Derechos Humanos, amplían el concepto de poder y exigen modificar el argumento. ${ }^{58}$

\footnotetext{
56. Id.

57. Véase Luigi Ferrajoli, supra, nota 16. Pág. 108.

58. Véase Francisco Javier Ansuategui Roig, supra, nota 55.
} 


\section{REFERENCIAS}

Adela Cortina. La dimensión pública de las éticas aplicadas. Revista Iberoamericana de Educación 9. 2000. Págs. 45-64.

Antonio Enrique Pérez Luño. Kant y los Derechos Humanos. Primera parte: El papel de Kant en la formación histórica de los derechos humanos. Dirs. Gregorio Peces-Barba Martínez, Eusebio Fernández García y Rafael Asís Roig. Historia de los Derechos Fundamentales. TOMO II: SIGLO XVIII. Volumen II: LA FILOSOFÍA DE los Derechos Humanos. Dykinson. (2001).

Boaventura de Sousa Santos. Sociología JuRÍdica CRÍTICA: PARA UN NUEVO SENTIDO COMÚN DEL DERECHO. Editorial Trotta. (2008).

Charles de Secondat Barón de Montesquieu. Del espíritu DE LAS LEYES. Tecnos. (1985).

David Held y Anthony McGrew. Globalización/AntiGLOBALIZACIÓN: SOBRE LA RECONSTRUCCIÓN DEL ORDEN MUNDIAL. Paidós. (2003).

Felipe Gómez Isa. Derechos humanos y globalización. EL DESAFÍO DEL DESARROLLO DE LOS DERECHOS HUMANOS. Propuestas locales para otra globalización. Hegoa. (2007).

Francisco Javier Ansuategui Roig. Democracia constitucional, derechos y violencia institucional. PAPELES EL Tiempo de los Derechos 3. 2009.

Francisco Javier Ansuategui Roig. Derechos Humanos y Empresa en el Contexto de la Internacionalización. Revista de Políticas Públicas 1. 2013. Págs. 7-10.

Francisco Javier Ansuategui Roig. Derechos fundamentales $y$ tradiciones constitucionales comunes en la aplicación del Derecho Europeo. Papeles el Tiempo de los DeRECHOS 3. 2013. Pág. 1.

Gregorio Peces-Barba. Curso de derechos fundamentales. Teoría general. Colaboración de Rafael Asís Roig, Carlos Fernández Liesa y Ángel Llamas Cascón. Universidad Carlos III de Madrid. Boletín Oficial del Estado. (1999).

Ignacio Aymerich Ojea. Orígenes ideológicos de la distribución de responsabilidades públicas y privadas en la garantía de los derechos humanos. Eds. Francisco Javier Zamora, Jesús García Cívico y Lorena Sales. LA RESPONSABILIDAD DE LAS MULTINACIONALES POR VIOLACIONES DE LOS DERECHOS humanos. Cuadernos de la Cátedra Democracia y Derechos Humanos. (2013).

Isaiah Berlin. CuATro ensayos SOBRE LA LibERTAD. Alianza Editorial. (1988).
Jean Jacques Rousseau. Contrato Social. Colección Austral. (2001).

José Manuel Pureza. El PATRIMONio Común DE LA HUMANIDAD: ¿HACIA UN DeReCho INTERNACIONAL DE LA SolIDARIDAD? Editorial Trotta. (2002).

Joseph E. Stiglitz. Making globalization work. W.W. Norton \& Company. (2006).

Juan Hernández Zubizarreta. LAS EMPRESAS TRANSNACIONALES FRENTE A LOS DERECHOS HUMANOS: HISTORIA DE UNA ASIMETRÍA NORMATIVA: DE LA RESPONSABILIDAD SOCIAL CORPORATIVA A LAS REDES CONTRAHEGEMÓNICAS TRANSNACIONALES. Hegoa. (2009).

Juan Ramón Capella. Fruta prohibida: una AproximaCIÓN HISTÓRICO-TEORÉTICA AL ESTUDIO DEL DEREChO Y del Estado. Trotta. (1997).

Luigi Ferrajoli. Contra los poderes Salvajes Del MERCADO: para un constitucionalismo de Derecho PRIVADO. Disponible en http://biblio.juridicas.unam. $\mathrm{mx} / \mathrm{libros} / 1 / 349 / 8 . \mathrm{pdf}$

Luis Prieto Sanchís. Estudios SOBRe DeRechos FundAMENTALES. Editorial Debate. (1990).

Luis M. Alix Lloredo. La filosofía del derecho en tiempo de crisis: en torno al estatus epistemológico de la filosofía jurídica. Revista Telemática del Filosofía del Derecho 16. 2013. Pág. 13.

María José Fariñas Dulce. Globalización, ciudadanía y derechos humanos. CuAdernos "BARTOLOMÉ DE LAS Casas" del Instituto de Derechos Humanos "Bartolomé de las Casas". Dykinson. (2000).

Matthew J Gibney. La GLOBalización De LOS DEReChos HuMANOS. Crítica. (2003)

Norberto Bobbio. Liberalismo y Democracia. Fondo de Cultura Económica. (1993).

Olga Martín Ortega. Las empresas multinacionales Y DERECHOS HUMANOS EN DERECHO INTERNACIONAL. Bosch Internacional. (2008).

OXFAM. Riqueza, TENERLO TODO Y QUERER MÁs. (Enero de 2015).

Rafael Asís Roig. LAS PARAdOJAS DE LOS DERECHOS FUNDAMENTALES COMO LÍMITES AL PODER. Dykinson. (2000).

Silvina Ribotta. El malestar del mundo actual. RevisTa UNIversitas de Filosofía, Derecho y Política 8. (Julio de 2008). Págs. 57-22.

Wayne Ellwood. Globalización. Intermon Oxfam. (2005).

World Economic Forum. The Outlook on the Global Agenda. World Economic Forum. (2013). 